\title{
Ciclo de vida, estrutura domiciliar e migração no início do século XXI: o caso da Região Metropolitana de São Paulo
}

\author{
Life cycle, household structure and migration at the beginning \\ of the 21st century: the case of the São Paulo Metropolitan Region
}

Marden Campos

\begin{abstract}
Resumo
As migrações internas no Brasil vêm se alterando consideravelmente nas últimas décadas. Atualmente as grandes metrópoles se configuram como as principais áreas de articulação da mobilidade espacial da população no território, haja vista o volume de indivíduos que para elas se dirige e que, ao mesmo tempo, delas parte. 0 objetivo deste artigo é analisar as características dos imigrantes da Região Metropolitana de São Paulo - RMSP com base nos dados do Censo Demográfico de 2010. Os resultados mostram uma forte relação entre ciclo de vida, arranjo domiciliar e atributos sociodemográficos dos migrantes. Acredita-se que o avançado nível de urbanização da RMSP tem intensificado a seletividade migratória em relação tanto aos atributos individuais quanto às redes de suporte dos migrantes, configurando seus padrões de formação domiciliar nos locais de destino.
\end{abstract}

Palavras-chave: migração; São Paulo; arranjos domiciliares; idade; censo

\begin{abstract}
Internal migration has been changing considerably in recent decades in Brazil. Nowadays, large metropolises are the main areas of articulation of the population's spatial mobility in the territory, given the volume of individuals that go to them and, at the same time, depart from them. The objective of this article is to analyze characteristics of the internal migrants who went to the São Paulo Metropolitan Region based on data from the 2010 Demographic Census. The results show a strong relationship between life cycle, household structure and socio-demographic attributes of migrants. We believe that the region's advanced level of urbanization has led to the exacerbation of migratory selectivity in relation to the migrants' individual attributes and support networks, configuring their residence patterns at their destination.
\end{abstract}

Keywords: migration; São Paulo; household structure; age; census. 


\section{Introdução}

As migrações internas no Brasil vêm passando por alterações consideráveis nas últimas décadas. Caracterizadas, em meados do século XX, por famílias que partiam das regiões economicamente mais estagnadas do País em direção às capitais da região Sudeste e às principais áreas de fronteira agrícola e mineral do Norte e Centro-Oeste; a partir da década de 1980, começam a apresentar modificações tanto nos tipos de migrantes como nas regiões envolvidas nos processos migratórios. Nesse período, inicia-se uma desconcentração espacial da população, marcada pela redução dos saldos migratórios observados nas metrópoles do Sudeste e pela migração de retorno para as regiões tradicionais de emigração. Começam a ser observadas, também, seguidas ondas de emigração internacional. Isso ocorre, importante salientar, em adição aos antigos fluxos populacionais, que não cessam por completo. Configura-se, assim, o perfil atual da mobilidade no Brasil, marcada por forte circularidade da população e por novas formas de deslocamento espacial, como movimentos pendulares, mobilidade sazonal e migração de curta duração.

Em meio a toda essa complexidade, atualmente as grandes metrópoles assumem um novo papel, de centros articuladores da mobilidade da população pelo território. 0 volume de indivíduos que para elas se dirige e que delas parte continuamente, aliado à diversidade das formas de deslocamento espacial, além das dificuldades de estabelecimento e moradia nos grandes centros urbanos, tende a intensificar a seletividade da migração em relação a diversos atributos individuais e familiares.
0 objetivo deste artigo é analisar as características dos migrantes que se dirigiram para a Região Metropolitana de São Paulo RMSP entre 2000 e 2010, com origem em outros municípios do País, com base nos dados do Censo Demográfico de 2010, realizado pelo Instituto Brasileiros de Geografia e Estatística.

As variáveis principais utilizadas para a análise são os perfis etários de migração (indicadores de ciclo de vida individual) e a composição do domicílio em termo de migrantes (indicador de estrutura domiciliar de migração). Para aprofundamento do estudo, serão utilizadas as variáveis sexo, unidade da federação de nascimento e de residência anterior, nível de instrução, atividade econômica e renda.

0 uso dos censos demográficos para estudos de migração apresenta uma grande vantagem que é a análise da composição domiciliar dos migrantes nas regiões de destino, possibilitando, dentre outros aspectos, estudarmos um tópico de grande relevância e que ainda é pouco estudado no Brasil: a relação entre migração e estrutura domiciliar.

\section{Aspectos espaciais}

\section{A unidade espacial de análise}

A escolha da RMSP como unidade de investigação deve-se ao fato de ela ser a maior metrópole do País, em que há maior complexidade da dinâmica urbana em face das outras regiões metropolitanas brasileiras. Desse modo, seria um espaço que permitiria observar de forma privilegiada como os processos demográficos se comportam em avançados estágios de metropolização. Referimo-nos aqui à 
"hiperseletividade migratória" e ao aguçamento das estratégias de adaptação que precisam ser adotadas pelos migrantes para se estabelecerem nos locais de destino.

Embora a RMSP tenha assistido a um processo de desconcentração espacial das atividades industriais que abrigava no passado, como nos mostra Cunha (2015), ela continua sendo a maior, mais rica e, economicamente, mais dinâmica região metropolitana do País, centro financeiro, comercial e de serviços nos moldes das grandes cidades globais do novo século. No estudo Regiões de Influência das Cidades, realizado pelo IBGE em 2007, que hierarquiza os centros urbanos nacionais segundo níveis de centralidade e de presença de equipamentos e serviços, São Paulo foi a única região alocada no primeiro nível territorial, classificada como grande metrópole nacional. Concentrava, à época do estudo, cerca de $28 \%$ da população brasileira e 40,5\% do seu Produto Interno Bruto (IBGE, 2008).

\section{As migrações internas recentes no Brasil}

A segunda metade do século $X X$ foi marcada por intensos movimentos migratórios entre as Unidades da Federação brasileiras. Dentro do processo de industrialização e modernização da sociedade, um grande contingente populacional partiu das áreas economicamente mais estagnadas do País para regiões que apresentavam crescente dinamismo econômico e oportunidades de emprego. A concentração industrial nas grandes cidades atraiu a população das áreas rurais, assim como das áreas urbanas menos desenvolvidas. Como os investimentos industriais concentravam-se nas metrópoles da região Sudeste, principalmente em São Paulo e no Rio de Janeiro, os principais fluxos populacionais do período direcionaram-se para esses locais. É nesse sentido que, referindo-se ao padrão migratório interestadual brasileiro observado entre 1950 e 1980, Brito (2002) afirma que nossas principais correntes migratórias ligavam regiões populosas e economicamente estagnadas, como Minas Gerais e os estados do Nordeste, com as áreas de elevado dinamismo econômico do País, representadas pelas metrópoles e por regiões de fronteira agrícola do Sul e Centro-Oeste. Nesse período, acredita-se que São Paulo recebeu mais de 1,7 milhão de imigrantes em termos absolutos (Ribeiro, Carvalho e Wong, 1996).

Esse processo atingiu seu auge nas décadas de 1960 e 1970. A partir desse período, começou a haver uma mudança nas migrações internas do País. Segundo Ribeiro, Carvalho e Wong (1996), as perdas populacionais de Minas Gerais e do Nordeste começaram a diminuir, enquanto o número de migrantes de retorno para essas regiões começou a aumentar. Nesse período, o estado de São Paulo alcançava o limite de sua capacidade de absorção de migrantes e tornava-se também um estado "expulsor" de população para o restante do Brasil.

Esse processo tem sido atribuído a mudanças na estrutura produtiva nacional, às seguidas crises econômicas e ao esgotamento da capacidade de absorção dos excedentes populacionais pelos antigos centros do Sudeste. 0 chamado "êxodo rural" perde força para as novas formas de mobilidade espacial (Rigotti, 1999). Conforme destaca Brito (2002), as virtudes das grandes cidades desapareceram diante 
da violência urbana, do desemprego, das dificuldades de acesso aos serviços públicos básicos e à moradia. Diminuíram, então, os ganhos populacionais de São Paulo e Rio de Janeiro, enquanto o Nordeste e Minas Gerais passaram a perder menos população. Ainda segundo Brito (ibid.), a maioria dos emigrantes de São Paulo que se dirigiram para o Nordeste e para Minas Gerais nesse período constituía-se de migrantes de retorno. Entre 1999 e 2004, estima-se que, dentre os migrantes provenientes de São Paulo, os retornados correspondam a $43 \%$ dos indivíduos que chegaram em Minas Gerais. Em relação ao Nordeste, esse percentual superou $60 \%$ dos migrantes, e, no caso do Ceará, correspondeu a 76\% dos imigrantes (Ribeiro, Carvalho e Wong, 1996).

Conforme destacado, as novas modalidades de deslocamento intensificaram-se sem que os antigos fluxos populacionais tivessem terminado. Nesse sentido, as grandes metrópoles passam a se configurar como centros de redistribuição da população, comportando-se como "nós" ou espaços centrais nos sistemas e redes de migração interna e internacional do Brasil. Ao mesmo tempo que continuam a receber um número significativo de migrantes, são também o principal local de origem daqueles que se dirigem para municípios de pequeno e médio porte, assim como para as áreas rurais.

0 presente trabalho parte do pressuposto de que a intensidade desses processos na RMSP favorece a observação de uma seletividade da migração no que tange às estratégias que os migrantes adotam para se estabelecerem em ambientes urbanos em termos de configuração de arranjos domiciliares.

\section{Aspectos sociodemográficos}

\author{
Seletividade etária da migração \\ e ciclo de vida
}

A seletividade da migração a atributos individuais é um fenômeno destacado pelos estudiosos da migração há décadas. 0 clássico trabalho de Everet Lee que, em 1966, propôs um modelo de análise das migrações destacava, de forma enfática, a seletividade migratória, principalmente em relação à idade. Em seu modelo analítico, em que a migração ocorria devido a um jogo de forças entre fatores de expulsão e de atração presentes nos locais de origem e de destino, o autor reitera diversas vezes que esses fatores afetam pessoas distintas de maneira distinta. Segundo ele, as migrações são seletivas em razão de as pessoas responderem de forma diferente aos fatores desencadeadores da migração (Lee, 1980, p. 111). Desse modo, a forma como os estímulos e obstáculos exercem sobre os indivíduos irá depender, em grande medida, do momento da vida por ele vivenciado, o que o autor denomina "etapa do ciclo vital" (ibid., p. 102). As migrações são tratadas por ele como rites de passages. Segundo essa perspectiva, à medida que a idade avança, o indivíduo vai atravessando etapas do ciclo de vida que alteram suas preferências quanto à localização domiciliar e, consequentemente, estimulam ou inibem a migração. Além das abordagens teóricas (por exemplo, Borjas, 1996 e De Jong e Gardner, 1981), vários trabalhos empíricos destacam a relação entre idade e migração (Heaton, Clifford e Fuguitt, 1981; Radcliffe, 
1992; Bures,1997; Kallan,1993; Golgher,2001; Marques e Rodrigues, 2006).

A seletividade etária da migração é algo tão marcante que alguns estudiosos desenvolveram modelos etários de migração, calcados em regularidades empíricas observadas em diversas regiões. Rogers e Castro (1981) verificaram que as taxas específicas de migração por idade - calculadas dividindo-se o número de migrantes pelo total de pessoas-ano em cada idade - exibiam persistentes regularidades entre várias populações. Logo, essas taxas puderam ser expressas por meio de fórmulas matemáticas. Conceitualmente, eles basearam-se na ideia de que as transições ocorridas ao longo do ciclo de vida interferem na propensão migratória do indivíduo. "The most prominent regularity found in empirical schedules of age-specific migration rates is the selectivity of migration with respect to age" (ibid., 1982, p. 155). A partir do cálculo de taxas específicas de migração por idade para diferentes populações, esses autores constataram que, embora a intensidade (nível) com que os indivíduos de cada população migravam variasse consideravelmente, o perfil (padrão) exibido pelas taxas migratórias apresentava persistente regularidade. Alguns autores, inclusive, aplicaram essas ideias aos fluxos migratórios observados no Brasil (Amaral, 2002; Machado, 2005; Januzzi, 1995), buscando identificar indícios dos motivos da migração a partir da análise dos perfis etários.

Para os termos da investigação que se propõe no presente trabalho, de relacionar migração, com idade e arranjos domiciliares, a utilidade desses modelos reside nos indicativos que a distribuição etária dos migrantes fornece sobre qual unidade de análise deve ser privilegiada no estudo de determinado fluxo migratório. Conforme pontuam Castro e Rogers (1983), os perfis etários de migração podem ser divididos em dois tipos: (1) um primeiro, marcado pela concentração (moda) de migrantes no entorno de idades adultas jovens, que seria indicativo de migrações individuais; (2) um outro em que, além do "pico migratório" nas idades laborais, há também uma parcela considerável de crianças entre os migrantes - em algumas populações também de idosos - indicando uma migração de tipo familiar.

Esses arcabouços analíticos se baseiam na ideia de que, à medida que a idade avança, os indivíduos atravessam etapas para as quais são socialmente estabelecidos papéis determinados (Glick, 1989). Essas fases da vida como, por exemplo, o casamento, o nascimento dos filhos, a saída do domicílio e a viuvez, teriam forte ligação com a propensão migratória dos indivíduos. Isso decorreria dos ajustes em termos de tamanho e localização dos domicílios que, em alguns casos, levariam à migração. Assim, as crianças necessitariam viver, por exemplo, em locais que possuem escolas, os adultos em locais com opção de trabalho e os idosos em locais que provêm opções de descanso, lazer e suporte. ${ }^{1}$

\section{Redes de suporte e arranjos domiciliares de migrantes}

Há décadas que os estudiosos da migração destacam o papel preponderante das redes sociais nos movimentos migratórios.

Em termos gerais, a rede social reflete a gama de relações pessoais que a pessoa mantém (Litwin, 1995). Tratando especificamente 
das redes sociais e da migração, podemos defini-las como conjuntos de laços interpessoais que ligam potenciais migrantes com migrantes de fato e com não migrantes nas áreas de origem e destino (Massey, 1990). Os contatos dos migrantes no destino, por exemplo, são importantes ao reduzirem o risco da migração e facilitarem a adaptação. Nesse sentido, torna-se claro o papel do capital social dos migrantes em suas estratégias de migração (Taylor, 1986).

Dentre as diversas modalidades em que uma rede de apoio é utilizada como suporte ao migrante, destacam-se a corresidência ou estruturação de arranjos domiciliares que visam, entre outros objetivos, o compartilhamento de recursos de diversas naturezas entre migrante e não migrantes. As famílias podem ser consideradas, em muitos casos, as "unidades decisórias" por excelência da migração, dado que é, em seu âmbito, que muitas vezes se decide quem, quando e para onde será realizada a migração. Acima de tudo, inclusive, muitas vezes, é a família toda - em termos de indivíduos que vivem juntos no mesmo domicílio - que migra conjuntamente.

Essas ideias estão contidas em pressupostos de diferentes abordagens teóricas que se dedicam ao estudo das migrações, como, pelo lado da economia, nas Teorias do Capital Humano (Borjas e Bronars, 1991; Mincer, 1978) e na chamada Nova Economia da Migração do Trabalho (Stark e Taylor, 1991; Stark e Bloom, 1985). Correntes sociológicas também destacam a estrutura familiar como determinante do comportamento migratório individual (Harbinson, 1981), das redes de transferências de recursos (Wolf, 1994) e das análises de tomada de decisão (Silverstein, 2006).

\section{Dados e método}

0 presente trabalho baseia-se em uma análise demográfica dos quesitos censitários de migração do Censo Demográfico de 2010. 0 foco da análise são os perfis etários exibidos por diferentes categorias de migrantes e as suas implicações em termos de formação do arranjo domiciliar. Outras variáveis coletadas pelo Censo, como atividade econômica, renda e nível de instrução, serão utilizadas com vista a enriquecer as análises.

Inicialmente, é preciso demarcar a distinção entre os conceitos de família e domicílio em termos de dados censitários. Segundo o IBGE (2010), "domicílio é o local estruturalmente separado e independente que se destina a servir de habitação para uma ou mais pessoas". Família seria o "conjunto de pessoas ligadas por laços de parentesco, dependência doméstica ou normas de convivência, residentes na mesma unidade domiciliar, ou pessoa que mora só em uma unidade domiciliar" (grifos nossos).

Contudo, fora das categorias censitárias, o conceito de família pode extrapolar a unidade domiciliar. Esse conceito mais amplo é descrito por Medeiros, Osorio e Varella (2002) como um conjunto de pessoas com laços reconhecidos de parentesco, independentemente do local de residência. Nesse sentido, Burch (1995, p. 99) destaca que a separação espacial pode não implicar o isolamento dos familiares: "four walls of the housing unit used to define it are too small and too arbitrary to capture the social, economic and psychological realities".

As análises realizadas no presente artigo serão feitas com base no domicílio dos migrantes. 
No que tange à migração, os censos são a base de dados mais completa existente no País. Há informações sobre a unidade da federação ou país estrangeiro de nascimento, o tempo de moradia na unidade da federação e a unidade da federação de residência anterior, além da unidade da federação e do município de residência 5 anos exatos antes da data de referência de cada censo.

0 IBGE categoriza como migrante 0 indivíduo que mudou de município ao menos uma vez na vida anteriormente à data de referência de um censo. A diversidade de quesitos presentes no questionário permite separar aqueles que moravam em um município diferente do que nasceram; os que haviam residido em município diferente na década anterior ao censo e, por fim, os que residiam em um município diferente exatos 5 anos antes do censo. É possível também combinar essas abordagens, enriquecendo-as ao reconhecer mais de uma etapa migratória do indivíduo.

É importante salientar que os dados dos censos apenas fornecem o estoque de migrantes captados pelo censo, que estavam vivos e não reemigraram da região de estudo. 0 ato de migrar ou a "migração" propriamente dita, em termos de fluxo, não é captado pelos censos. Nesses termos, Carvalho (2000, p. 2) resume: "enquanto o termo migrante envolve a atenção ao aspecto individual, o termo migração refere-se ao conjunto de todas as migrações individuais feitas no período".

Optou-se por utilizar, na presente análise, as informações sobre o tempo de residência dos indivíduos na RMPS, combinado com seus locais de residência anterior. Essa informação possui a vantagem, em relação às outras informações presentes nos censos, de identificar todos os migrantes da década, incluindo os migrantes interestaduais de retorno. Além disso, reporta à migração que ocorreu diretamente para a região de destino estudada, sem etapas intermediárias. Por possuir um horizonte temporal mais amplo (10 anos) em relação ao quesito de data-fixa (5 anos), capta um número maior de migrantes e, assim, aumenta a precisão das estimativas, dado que o quesito tem origem amostral.

A variável construída para se analisar o arranjo domiciliar do migrante foi denominada "estrutura domiciliar da migração". Ela corresponde à composição do domicílio em termos de imigrantes da RMSP na década anterior ao Censo. Os imigrantes foram divididos em 4 categorias: (1) os que viviam sós após a migração; (2) os que viviam apenas com o cônjuge, sendo este também migrante da década (incluindo os que tiveram filho na RMSP após a migração); (3) os que viviam em domicílios nos quais todos os membros eram migrantes da RMSP na década; (4) os que viviam em domicílios nos quais residia pelo menos um indivíduo que não migrou para a RMSP na década de 2000 (embora pudesse ter imigrado em um momento anterior).

Ressalta-se que, devido às características da informação censitária, só possuímos informação do domicílio do migrante no destino. Essa informação se refere apenas aos indivíduos que estavam vivos na data de referência do Censo e que não reemigraram. Por exemplo, na categoria "Migraram sós" estão representados os que viviam sós na data de referência dos censos, mesmo que tenham migrado com outros indivíduos, que, porventura, tenham 
falecido ou se mudado para outro domicílio antes do censo. Sendo assim, essa variável será considerada uma aproximação da composição familiar do grupo migrante. Acredita-se, contudo, que os erros que esse procedimento possa incutir são decrescentes quando nos aproximamos, temporalmente, da data de realização do Censo e, por isso, não deverão afetar significativamente a informação da década imediatamente anterior.

\section{Resultados}

Entre 2000 e 2010, a RMSP recebeu 2.281.110 imigrantes de outros municípios brasileiros. Destes, 1.210 .675 (53\%) vinham do próprio estado de São Paulo e 1.070.435 (47\%) vinha de municípios localizados em outras unidades da federação. Os principais estados de origem dos migrantes foram Bahia, Pernambuco e Minas

Tabela 1 - Imigrantes da Região Metropolitana de São Paulo, total e percentual, segundo principais Unidades da Federação de residência anterior - 2010

\begin{tabular}{l|c|c}
\hline \multirow{2}{*}{ Unidade da Federação de residência anterior } & \multicolumn{2}{|c}{ Imigrantes } \\
\cline { 2 - 3 } & Total & \% \\
\hline São Paulo & 1.210 .675 & 12,9 \\
Bahia & 294.169 & 5,9 \\
Pernambuco & 133.515 & 5,6 \\
Minas Gerais & 127.129 & 3,8 \\
Ceará & 87.790 & 2,9 \\
Piauí & 67.164 & 2,3 \\
Alagoas & 52.155 & 2,3 \\
Paraíba & 52.031 & 2,1 \\
Rio de Janeiro & 48.246 & 2,1 \\
Paraná & 47.248 & 1,6 \\
Maranhão & 35.767 & 5,5 \\
Demais Unidades da Federação & 125.221 & 100,0 \\
\hline Total & 2.281 .110 & 2 \\
\hline
\end{tabular}

Fonte: IBGE (2010). 
Gerais, que, juntos, somavam pouco mais da metade dos que chegaram à RMSP na década anterior ao Censo (51,3\%), conforme a Tabela 1. A alta concentração das regiões de origem dos imigrantes em poucas unidades da federação (10 UFs foram responsáveis por quase $90 \%$ da imigração) é um indicativo de que há fluxos migratórios espacialmente específicos destinados à RMSP, provavelmente estruturados por redes sociais de migração.

Os imigrantes intra e interestaduais apresentavam diferenças marcantes quanto à condição social, aqui medida quanto ao nível de instrução. 0 Gráfico 1 mostra a distribuição de indivíduos com 30 anos de idade ou mais segundo o nível de instrução, para os não migrantes, imigrantes interestaduais e intraestaduais.

Pode-se perceber que os indivíduos que vieram de outras unidades da federação apresentam níveis de instrução inferiores. Entre eles, mais da metade foi classificada como "sem instrução ou com nível fundamental incompleto". Esses indivíduos também possuem os menores percentuais de população com nível superior completo. Além disso, os imigrantes com origem em municípios do estado de São Paulo apresentam maior escolaridade, inclusive quando comparados com os não migrantes.

Gráfico 1 - Distribuição percentual dos imigrantes da RMSP segundo nível de instrução, por categoria migratória - 2010

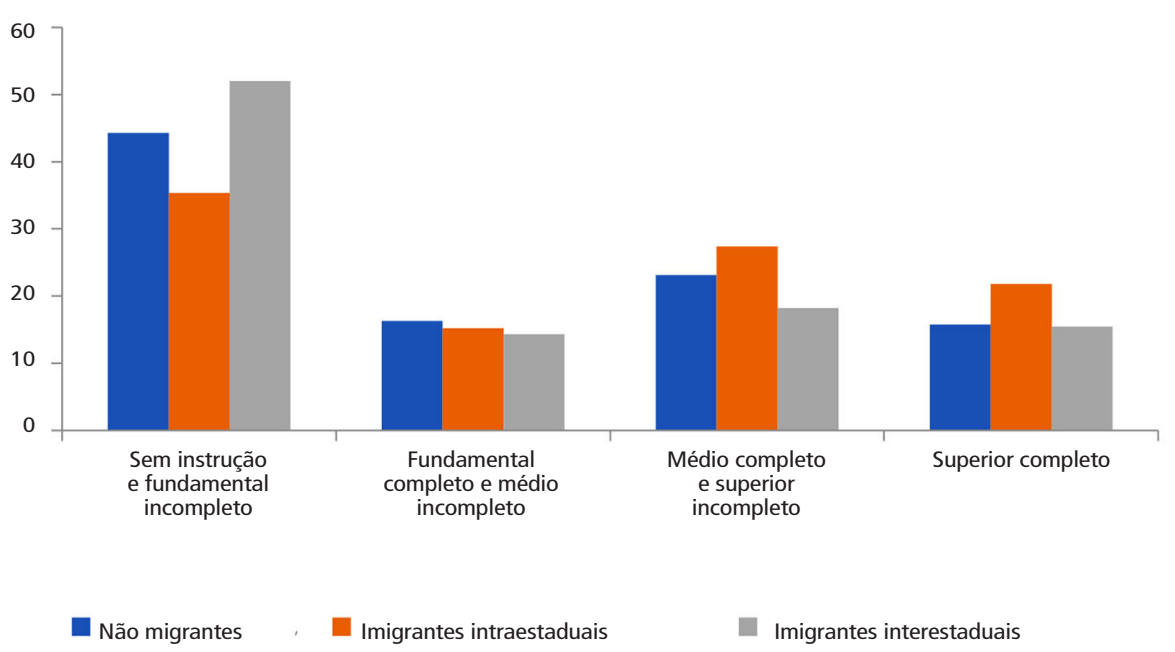

Fonte: IBGE (2010). 
A inserção dos imigrantes no mercado de trabalho, segundo os principais setores de atividade em que trabalhavam, é apresentada na Tabela 2, comparativamente aos não migrantes, separados homens e mulheres. As principais atividades econômicas dos imigrantes, tanto para homens como para mulheres, eram as mesmas dos não migrantes, embora houvesse variação da importância de cada divisão de atividade segundo condição migratória. No caso dos homens, o comércio empregava um percentual semelhante para todas as categorias analisadas, mas empregava ligeiramente menos imigrantes intraestaduais. Já a construção empregava quase o dobro de imigrantes interestaduais, em termos percentuais, do que de não migrantes e de imigrantes intraestaduais. No caso das mulheres, o comércio foi o que mais empregou, tanto as não migrantes como as imigrantes intraestaduais, enquanto 0 serviço doméstico foi a principal atividade das imigrantes interestaduais. Estas últimas também tiveram uma inserção menor nas áreas de saúde e educação.

A partir da caracterização feita até aqui, vê-se que os migrantes que vêm de outros municípios do estado de São Paulo para a RMSP se encontram, em termo de escolaridade e inserção no mercado de trabalho, em categorias consideradas mais favoráveis do que aqueles que tiveram como origem outras unidades da federação.

Tabela 2 - Distribuição percentual dos não-migrantes e dos imigrantes intra e interestaduais, por sexo, segundo principais atividades econômicas - 2010

\begin{tabular}{l|c|c|c}
\hline \multicolumn{1}{c|}{ Atividade econômica* } & Não migrantes & Imigrante intraestadual & Imigrante interestadual \\
\hline \multicolumn{3}{c|}{} & \multicolumn{2}{c}{ Homens } \\
\hline Comércio & 16,2 & 14,7 & 16,3 \\
Construção & 11,0 & 10,3 & 20,2 \\
Transporte & 7,4 & 6,7 & 5,3 \\
Fab. produtos de metal & 5,8 & 5,0 & 5,3 \\
Com. e reparação de veículos & 3,9 & 3,5 & 2,8 \\
Alimentação & 3,9 & 3,0 & 7,2 \\
Demais atividades & 51,7 & 56,8 & 43,0 \\
Total & 100,0 & 100,0 & 100,0 \\
\hline & & Mulheres & 19,6 \\
\hline Comércio & 16,9 & 16,7 & 25,4 \\
Serviços domésticos & 15,4 & 12,4 & 4,7 \\
Educação & 9,3 & 9,7 & 5,3 \\
Atenção à saúde & 7,8 & 8,3 & 45,1 \\
Demais atividades & 50,6 & 53,0 & 100,0 \\
Total & 100,0 & 100,0 & \\
\hline
\end{tabular}

*Segundo divisão CNAE em vigor em 2010.

Fonte: IBGE (2010). 
A fim de identificar as estratégias de formação do arranjo domiciliar utilizadas pelos imigrantes da RMSP na década de 2000, será feita uma análise de seus padrões demográficos e da estrutura domiciliar de migração.

Em relação aos aspectos demográficos, observamos que as mulheres representavam $51,3 \%$ dos imigrantes, configurando uma razão de sexo de 95\%, o que mostra equilíbrio na distribuição dos imigrantes por sexo. Também, havia grande variação dos imigrantes em relação à idade. 0 Gráfico 2 mostra a distribuição dos imigrantes por grupo de idade, tanto para os que vieram do estado de São Paulo como de outras UFs, comparativamente à população não migrante.

A distribuição etária dos não migrantes não indica grande influência da migração, aproximando-se de uma distribuição etária típica das regiões brasileiras que se encontram em fase adiantada do processo de transição demográfica. A composição etária dos imigrantes, por sua vez, atesta alta seletividade etária, dado que há elevada concentração em idades específicas. Ademais, há uma diferença marcante entre os que vieram de municípios do próprio estado de São Paulo (imigrantes intraestaduais) em relação aos provenientes de outras UFs (imigrantes interestaduais). Entre os imigrantes intraestaduais, há uma concentração de indivíduos com 25 a 39 anos de idade, acompanhada de crianças com 5 e 9 anos de idade. Também os migrantes que vieram de outras Unidades da Federação se concentravam-se principalmente entre os 20 e 34 anos de idade.

\section{Gráfico 2 - Distribuição percentual dos imigrantes de última etapa por origem (intra ou interestadual) e dos não migrantes - RMSP, 2010}

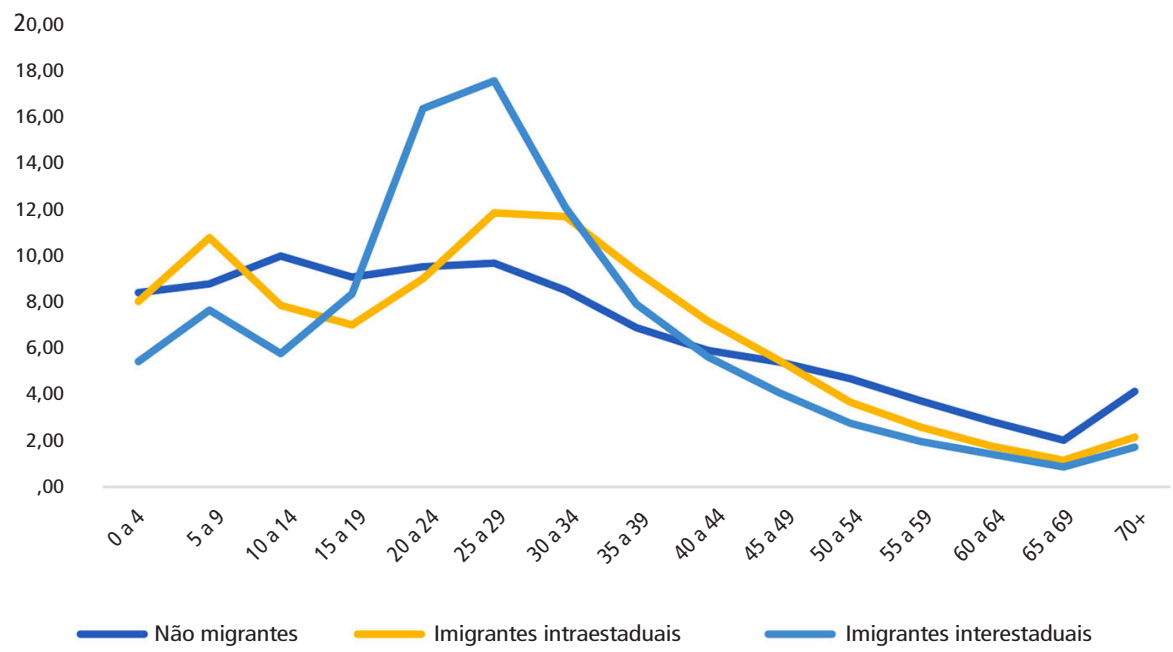


Com base na interpretação dos padrões etários de migração feitos por Rogers e Castro (1981), percebe-se um padrão etário típico de "migração familiar" entre aqueles cuja procedência era o próprio estado de São Paulo, ao passo que o padrão etário dos que vieram de outras UFs é típico da "migração individual" descrita pelos autores.

A análise da estrutura domiciliar da migração, apresentada na Tabela 3, avança um pouco mais no detalhamento dessa questão. Em termos gerais, percebemos que a maioria dos migrantes residia em domicílios em que todos os moradores migraram para RMSP na década anterior ao Censo, caracterizando uma migração "em grupo". Em seguida, vemos que aproximadamente 35\% dos imigrantes se dirigiram para domicílios que já estavam estabelecidos antes de sua chegada. Apenas um número reduzido migrou só ou apenas com o cônjuge. Isso mostra como a análise da estrutura domiciliar da migração é um aspecto extremamente relevante para o estudo das migrações atuais no Brasil.

Os imigrantes cuja origem foram os municípios do próprio estado de São Paulo apresentavam um percentual ligeiramente superior de indivíduos que migraram em companhia de todos os membros do domicílio, relativamente aos que vieram de outras UFs.

Tabela 3 - Distribuição percentual dos imigrantes da RMSP segundo estrutura domiciliar da migração e unidade da federação de origem - 2010

\begin{tabular}{l|c|c|c|c}
\hline \multirow{2}{*}{$\begin{array}{c}\text { Unidade da Federação } \\
\text { do município de origem }\end{array}$} & Sós & $\begin{array}{c}\text { Apenas responsável } \\
\text { e cônjuge }\end{array}$ & Todo domicílio & $\begin{array}{c}\text { Para um domicílio } \\
\text { pré-estabelecido }\end{array}$ \\
\cline { 2 - 5 } & 4,1 & 8,2 & 55,3 & 32,3 \\
\hline Imigrante Intraestadual & 4,5 & 8,8 & 49,1 & 37,6 \\
\hline Imigrante Interestadual & 3,4 & 7,8 & 50,6 & 38,2 \\
Bahia & 3,3 & 8,7 & 48,6 & 39,4 \\
Pernambuco & 5,0 & 8,1 & 45,2 & 41,7 \\
Minas Gerais & 3,3 & 9,0 & 52,5 & 35,2 \\
Ceará & 3,0 & 8,8 & 57,1 & 31,1 \\
Piauí & 2,6 & 7,0 & 54,2 & 36,2 \\
Alagoas & 3,1 & 9,1 & 49,9 & 37,9 \\
Paraíba & 8,4 & 12,4 & 48,5 & 30,8 \\
Rio de Janeiro & 6,0 & 9,9 & 42,9 & 41,3 \\
Paraná & 2,8 & 7,2 & 50,7 & 39,2 \\
Maranhão & 7,0 & 9,9 & 46,2 & 36,8 \\
Demais UFs & 4,3 & 8,5 & 52,3 & 34,9 \\
\hline Total & & & \\
\hline
\end{tabular}

Fonte: IBGE (2010). 
A Tabela 2 apresenta as principais UFs de origem dos imigrantes da RMSP, de forma desagregada, para que possamos aprofundar nossa análise em detalhes. Vê-se que os percentuais de migração com o domicílio todo são relativamente mais baixos entre os imigrantes interestaduais, exceto para os que vieram do Piauí. Enquanto a migração em direção a um domicílio preestabelecido, onde viviam não migrantes, é mais relevante entre os imigrantes interestaduais.

Interpretando esses dados diante dos perfis etários de migração descritos no Gráfico 2, levantamos a hipótese de que, se eles realizaram uma "migração individual", essa migração aconteceu, em grande parte, em direção a um domicílio já estabelecido. Isso seria um indício da existência de uma rede de suporte aos migrantes na RMSP.

Em relação à possibilidade de residir (e migrar) só, há farta literatura relacionando tal condição ao aumento do nível de renda do indivíduo (Camargos, Machado e Rodrigues, 2007; Lloyd-Sherlok, 2001; Palloni, 2001). 0 caso mais significativo a esse respeito se refere àqueles que tiveram origem no Rio de Janeiro (Tabela 2).

A Tabela 4 mostra a distribuição dos imigrantes com origem em diferentes UFs segundo a faixa de rendimento domiciliar per capita em salários mínimos.

Tabela 4 - Distribuição percentual dos imigrantes da RMSP segundo categorias de rendimento domiciliar per capita, em salários mínimos e Unidade da Federação de origem - 2010

\begin{tabular}{l|c|c|c|c|c|c}
\hline \multirow{2}{*}{$\begin{array}{l}\text { Unidade da Federação } \\
\text { do município de origem }\end{array}$} & \multicolumn{5}{|c}{ Rendimento domiciliar per capita em salários mínimos } \\
\cline { 2 - 7 } & $\mathbf{0}$ a 0,5 & $\mathbf{0 , 5}$ a 1 & $\mathbf{1}$ a 2 & $\mathbf{2}$ a 5 & $\mathbf{5}$ a 10 & $\mathbf{1 0}$ ou + \\
\hline Não migrantes & 23,0 & 25,1 & 25,4 & 17,2 & 5,8 & 3,4 \\
\hline Intraestadual & 15,0 & 23,6 & 24,4 & 20,4 & 8,3 & 4,6 \\
\hline Interestadual: & & & & & & \\
Bahia & 21,3 & 34,4 & 27,6 & 8,2 & 1,6 & 1,7 \\
Pernambuco & 23,6 & 32,6 & 27,3 & 7,8 & 1,5 & 1,9 \\
Minas Gerais & 14,0 & 24,4 & 27,5 & 16,5 & 6,5 & 6,2 \\
Ceará & 18,6 & 32,0 & 30,9 & 9,0 & 2,2 & 2,0 \\
Piauí & 19,8 & 37,7 & 28,7 & 7,2 & 1,1 & 1,2 \\
Alagoas & 28,0 & 33,4 & 23,4 & 7,3 & 0,9 & 1,0 \\
Paraíba & 18,5 & 34,8 & 30,9 & 7,3 & 1,8 & 1,5 \\
Rio de Janeiro & 8,7 & 13,9 & 17,0 & 18,7 & 16,8 & 19,4 \\
Paraná & 11,0 & 19,4 & 24,1 & 22,4 & 11,9 & 7,2 \\
Maranhão & 19,7 & 35,1 & 31,9 & 5,2 & 1,9 & 1,7 \\
\hline
\end{tabular}

Fonte: IBGE (2010). 
Pode-se perceber que os imigrantes com maiores rendimentos são os provenientes do Rio de Janeiro, cujo percentual dos que migraram sós é mais elevado. Piauí e Alagoas, com percentuais relativamente mais elevados de migração em grupo, possuem os imigrantes em pior situação econômica.

\section{Discussão}

0 presente trabalho procurou analisar as características dos imigrantes da RMSP na década de 2000 em termos de atributos socioeconômicos e demográficos, com destaque para a análise das estruturas domiciliares da migração. Os resultados mostram que há uma forte diferenciação dos migrantes em relação às categorias analisadas.

Os migrantes cuja origem foi um outro município do estado de São Paulo apresentavam maior renda e escolaridade, além de uma inserção no mercado de trabalho próxima à dos não migrantes e um perfil de migração familiar, com maior proporção de indivíduos que migraram em conjunto. Já os imigrantes cuja origem foi de outras UFs eram menos escolarizados e estavam mais concentrados nas atividades de construção, no caso dos homens, e em serviços domésticos, entre as mulheres. Esses indivíduos apresentavam uma renda inferior aos migrantes intraestaduais e, relativamente a esses, possuíam um percentual maior entre os que migraram para um domicílio preestabelecido.

A desagregação dos dados por UF mostrou uma acentuada diferenciação entre esses indivíduos. Aqueles que procederam do Piauí e Alagoas, por exemplo, cujas rendas eram relativamente menores que os demais, tiveram percentuais maiores de indivíduos migrando com o domicílio todo ou para um domicílio preestabelecido. Por outro lado, aqueles que tiveram como origem o Rio de Janeiro, com níveis de renda mais elevado, apresentaram maiores percentuais de indivíduos que migraram sós.

Em suma, pode-se "inferir" que os migrantes que se originaram de regiões socioeconomicamente mais favorecidas, em termos de renda e escolaridade, possivelmente tiveram maior "liberdade" quanto à escolha da estratégia de migração, como a possibilidade de migrarem sós ou apenas com o cônjuge. Já, os que vieram das regiões economicamente mais pobres do País e que se inseriram em atividades economicamente menos favorecidas apresentam indícios de necessitar de uma estrutura de suporte no destino para realizar a migração.

A região metropolitana de São Paulo recebeu um contingente significativo de migrantes na primeira década do século XXI. A análise das características individuais e domiciliares desses migrantes mostra a forte relação entre ciclo de vida, arranjo domiciliar e atributos sociodemográficos dos migrantes. Acredita-se que o avançado nível de urbanização presente na região em estudo levou à exacerbação da seletividade migratória tanto em termos individuais como de características das redes de suporte aos migrantes, em seu aspecto de padrões de formação domiciliar e corresidência.

Estudos posteriores poderão indicar diferenciações nesses padrões na região metropolitana estudada, assim como também em outras metrópoles brasileiras. Do mesmo modo, as análises aqui realizadas podem ser complementadas com dados referentes aos 
indivíduos que deixam a metrópole em direção a outras regiões do Brasil. 0 estudo serve, portanto, como referência inicial para esse tipo de análise, principalmente no que tange à estrutura domiciliar de migração, aspecto pouco estudado no País
0 estudo também mostra a forma como a imigração contribui, em termos demográficos e socioeconômicos, para a configuração social da maior metrópole do País, cuja dinâmica populacional continua fortemente ligada a outras regiões brasileiras.

\section{Marden Campos}

Universidade Federal de Minas Gerais, Faculdade de Filosofia e Ciências Humanas, Departamento de Sociologia. Belo Horizonte, MG/Brasil.

mardencampos@gmail.com

\section{Nota}

(1) Há uma outra abordagem, diferente da anterior, mas que também analisa a evolução dos indivíduos ao longo da vida, que podemos denominar "abordagem do curso de vida", numa tradução literal do termo life course. Sua preocupação se relaciona com as trajetórias e transições da vida e com seus efeitos nas vidas individuais (Elder Jr., 1985). O foco dessa abordagem, ligeiramente diferente da que estamos chamando de "ciclo de vida", está no papel das transições como modificadoras das trajetórias individuais, e não com etapas específicas do ciclo de vida e as performances e papéis a elas associadas (ibid. 1985 e 1994). Há controvérsias referentes à aplicação dessas análises em estudos empíricos, dado que as abordagens de ciclo e transição só poderiam ser observadas, stricto sensu, a partir de dados longitudinais. Como o presente trabalho baseia-se em um estudo pontual, seria oportuno classificar como uma análise de uma etapa ou momento do ciclo de vida. 


\section{Referências}

AMARAL, E. F. L. (2002). Funções de migração por idade e caracterização de migrantes das microrregiões de Goiás e Distrito Federal 1975-1979 e 1986-1990. Dissertação de Mestrado. Belo Horizonte, Universidade Federal de Minas Gerais.

BARBIERI, A. F. (2007). Mobilidade populacional, meio ambiente e uso da terra em áreas de fronteira: uma abordagem multiescalar. Revista Brasileira de Estudos Populacionais. Campinas, v. 24, n. 2, pp. 225-246.

BORJAS, G. J. (1996). Labor Economics. Nova York, Mac Graw Hill.

BORJAS, G. J. e BRONARS, S. G. (1991). Immigration and the family. Journal of Labor Economics. Chicago, v. 9, n. 2, pp. 123-148.

BRITO, F. (2002). "Brasil, final de século: a transição para um novo padrão migratório'? In: CARLEIAL, A. N. Transições migratórias. Fortaleza, Iplance.

BURCH, T. K. (1995). “Theories of household formation: progress and challenges”. In: IMHOFF, W. et al. (eds.). Household demography and household modeling. Nova York, Plenum Press.

BURES, R. (1997). "Migration and the life course: Is there a retirement transition?". International Journal of Population Geography. Chichester, v. 3, n. 2, pp. 109-119.

CAMARGOS, M. C. S.; MACHADO, C. J. e RODRIGUES, R. N. (2007). A relação entre renda e morar sozinho para idosos paulistanos. Revista Brasileira de Estudos da População. Campinas, v. 24, n. 1, pp. 37-51.

CARVALHO, J. A. M. (2000). Dados de migração de última etapa e data fixa do Censo Demográfico Brasileiro de 1991: uma análise de consistência. Revista Brasileira de Estudos de População. Campinas, v. 17, n. 1/2, pp. 87-96.

CARVALHO, J. A. M. et al. (1998). Minas Gerais, uma nova região de atração populacional? In: SEMINÁRIO SOBRE A ECONOMIA MINEIRA. Anais... Diamantina, UFMG/Cedeplar.

CASTRO, L. e ROGERS, A. (1983). What the age composition of migrants can tell us. Population Bulletin of the United Nations. Nova York, n. 15, pp. 63-79.

CUNHA, J. M. P. da. (2015). Mobilidade populacional e expansão urbana: o caso da Região Metropolitana de São Paulo. Campinas, Librum.

DE JONG, G. F. e GARDNER, R. W. (eds.). (1981). Migration decision making: multidisciplinary approaches to microlevel studies in developed and developing countries. Nova York, Pergamon Press.

ELDER Jr., G. H. (1985). "Perspectives on the life course”. In: ELDER Jr, G. H. (ed.). Life course dynamics: trajectories and transitions, 1968-1980. Nova York/Londres, Cornell University Press.

(1994). Time, human agency, and social change: perspectives on the life course. Social Psychology Quarterly. Washington, v. 57, n. 1, pp. 4-15.

GLICK, P. (1955). The life cycle of the family. Marriage and Family Living. Menasha, v. 17, pp. 3-9.

(1977). Uptading the life cycle of the family. Journal of Marriage and the Family. Menasha, v. 39, n. 1, pp. 5-13.

(1989). The life cycle and social change. Family Relations. Minneapolis, v. 38, n. 2, pp. 123-129. 
GOLGHER, A. B. (1998). Análise de fluxos de migrantes em Minas Gerais com base nos resultados de caracterização da região de estudo por técnica de grade of membership. In: ENCONTRO NACIONAL DE ESTUDOS POPULACIONAIS, 11. Anais... Belo Horizonte, Abep.

(2001). Os determinantes da migração e diferenciais entre migrantes e não migrantes em Minas Gerais. Tese de Doutorado. Belo Horizonte, Universidade Federal de Minas Gerais.

HARBINSON, S. F. (1981). "Family structure and family strategy in migration decision making”. In: DE JONG, G. F. e GARDNER, R. W. (eds.). Migration decision making: multidisciplinary approaches to microlevel studies in developed and developing countries. Nova York, Pergamon Press.

HEATON, T. B.; CLIFFORD, W. B. e FUGUITT, G. V. (1981). Temporal shifts in the determinants of young and elderly migration in nonmetropolitan areas. Social Forces. Chapel Hill, v. 60, n. 1, pp. 41-60.

INSTITUTO BRASILEIRO DE GEOGRAFIA E ESTATÍ́STICA - IBGE. (2003). Censo demográfico 2000: família e domicílios. Resultados da amostra. Rio de Janeiro, IBGE.

(2008). Regiões de influência das cidades: 2007. Rio de Janeiro, IBGE.

(2010). Microdados do censo demográfico 2010. Rio de Janeiro, IBGE.

JANUZZI, P. M. (1995). Perfis etários da migração por motivos e acompanhantes da mudança: evidências empíricas para São Paulo entre 1980 e 1993. Revista Brasileira de Estudos Populacionais. Brasília, v. 15, n. 2 , pp. $19-44$.

KALLAN, J. E. (1993). A multilevel analysis of elderly migration. Social Science Quarterly. Austin, Texas, v. 74 , n. 2, pp. $403-416$.

LEE, E. S. (1980 [1966]). “Uma teoria sobre a migração”. In: MOURA, H. A. (org.). Migração interna, textos selecionados: teorias e métodos de análise. Fortaleza, BNB.

LITWIN, H. (1995). The Social Network of Elderly Immigrants: an analytic typology. Journal of Aging Studies. Nova York, v. 9, n. 2, pp. 155-174.

LLOYD-SHERLOK, P. (2001). Living arrangements of older persons and poverty. United Nation Population Bulletin. Nova York, n. 42/43, Special Issue.

MACHADO, C. C. (2005). Estabelecimento de fluxos migratórios padrão para o Brasil: análise exploratória dos dados censitários de 1991 e 2000. In: ENCONTRO NACIONAL SOBRE MIGRAÇÃO, 4. Anais... Rio de Janeiro, Abep.

MARQUES, D. e RODRIGUES, L. (2006). Emigrantes e imigrantes de Belo Horizonte em relação ao restante da RMBH: uma aplicação do método "Grade of Membership" (GoM). In: ENCONTRO NACIONAL DE ESTUDOS POPULACIONAIS, 15. Desafios e oportunidades do crescimento zero. Anais... Campinas, Abep.

MASSEY, D. (1990). Social structure, household strategies and the cumulative causation of migration. Population Index. Princeton, v. 56, n. 1, pp. 3-26.

MASSEY, D. et al. (1998). Worlds in motion: understanding international migration at the end of the millennium. Oxford, Clarendon Press.

MATOS, R. E. S.; LOBO, C. e STEFANI, J. (2005). "Inversão de tendências históricas de migração entre Minas Gerais e São Paulo". In: MATOS, R. E. S. (org.). Espacialidades em rede: população, urbanização e migração no Brasil contemporâneo. Belo Horizonte, C/Arte. 
MCLANAHAN, S. S. e SORENSEN, A. B. (1985). "Life events and psychological well-being over the life course". In: ELDER Jr, G. H. (ed.). Life course dynamics - trajectories and transitions, 1968-1980. Nova York, Cornell University Press,

MEDEIROS, M.; OSORIO, R. G. e VARELLA, S. (2002). O levantamento de informações sobre as famílias nas PNADs de 1992 a 1999. Rio de Janeiro, Ipea (Texto para discussão, 860).

MINCER, J. (1978). Family Migration Decisions. The Journal of Political Economy. Chicago, v. 86, n. 5, pp. 749-773.

PALLONI, A. (2001). Living arrangements of older person. Population Bulletin of the United Nations. Nova York, n. 42/43.

RADCLIFFE, S. A. (1992). "Mountains, maidens and migration: gender and mobility in Peru”. In: CHANT, S. Gender and migration in developing countries. Londres, Belhaven Press.

RIBEIRO, J. T. e CARVALHO, J. A. M. (1998). A imigração para Minas Gerais no período 1981/1991, com especial enfoque na migração de retorno. In: ENCONTRO NACIONAL DE ESTUDO POPULACIONAIS, 11. Caxambu. Anais... [S.I], Abep.

RIBEIRO, J. T. L.; CARVALHO, J. A. M. e WONG, L. R. (1996). Migração de retorno: algumas possibilidades de mensuração. In: ENCONTRO NACIONAL DE ESTUDO POPULACIONAIS, 10. Caxambu. Anais... [S.I], Abep.

RIGOTTI, J. I. R. (1999). Técnicas de mensuração das migrações, a partir dos dados censitários aplicação aos casos de Minas Gerais e São Paulo. Tese de Doutorado. Belo Horizonte, Universidade Federal de Minas Gerais.

ROGERS, A. (1988). Age patterns of elderly migration: an international comparison. Demography. Seattle, v. 25, n. 3, pp. 355-370.

ROGERS, A. e CASTRO, L. (1981). Model migration schedules. Luxemburgo, IIASA (Research Report, WP-81-30).

(1982). "Migration”. In: ROGERS, A. e WILLEKENS, F. J. Migration and settlement. Dordrecht, D Reidel Publishing Company.

SILVERSTEIN, M. (2006). "Intergerational family transfers in social context". In: BINSTOCK, R. H. e GEORGE, L. K (eds.). Handbook of aging and the social sciences. Burlington, Academic Press/ Elsevier.

STARK, O. e BLOOM, D. (1985). The new economics of labor migration. AEA Papers and Proceedings: frontiers in demographic economics. Pittsburgh, v. 75, n. 2, pp. 173-178.

STARK, O. e TAYLOR, E. (1991). Migration incentives, migration types: the role of relative deprivation. The Economic Journal. St. Andrews, v. 101, n. 408, pp. 1163-1178.

TAYLOR, J. E. (1986). “Differential migration, networks, information an risks”. In: STARK, O. Migration, human capital and development. Greenwich, Connecticut, Jai Press.

WOLF, D. A. (1994). "The elderly and their kin: patterns of availability and access". In: MARTIN, L. e PRESTON, S. (eds.). Demography of Aging. Washington, National Academy Press.

Texto recebido em 15/set/2017

Texto aprovado em 27/out/2017 